\title{
A TEORIA DA COOPERAÇÃO EM ROBERT AXELROD E A PRÁTICA DE ILÍCITOS CONCORRENCIAIS
}

\section{THE THEORY OF COOPERATION IN ROBERT AXELROD AND THE PRACTICE OF ANTI-COMPETITIVE ACTS}

\author{
${ }^{1}$ Daniel Fernando Pastre
}

\section{RESUMO}

A proposta do presente artigo é fazer uma avaliação da teoria da cooperação de Robert Axelrod e, a partir dessa teoria, extrair uma relação entre a cooperação (ou o excesso de cooperação e a cooperação negativa) com as práticas anticoncorrenciais, dentro de um determinado quadro institucional, visando, ao final, verificar se, quando e como as advertências e estratégias para promover a cooperação relacionam-se a atual estrutura de incentivos e se, quando e como é possível que aquelas gerem excesso de cooperação ou cooperação negativa, fomentando a prática de ilícitos concorrenciais. Do mesmo modo, busca-se, com o presente artigo, propor uma revisão do Dilema do Prisioneiro, adequando-o ao quadro institucional brasileiro, para que a relação entre a cooperação e a prática de atos anticompetitivos seja realizada em base mais condizente com ao cenário nacional.

Palavras-chave: Direito antitruste, Políticas públicas, Desenvolvimento, Cooperação, Robert axelrod

\begin{abstract}
The purpose of this article is to make an assessment of cooperation theory of Robert Axelrod and, from this theory, extract a relationship between cooperation (or excessive cooperation and the negative cooperation) with anti-competitive practices, inside one specific institutional framework, and, at the end, check if, when and how the suggestions and strategies to promote cooperation are related to the current structure of incentives and if, when and how can those generates an excessive cooperation or negative cooperation, promoting anti-competitive practices. Similarly, this article aims a revision of the Prisoner's Dilemma, adapting it to the brazilian institutional framework, so, that the relationship between cooperation and the practice of anti-competitive acts are performed in more consistent basis with the national scene.
\end{abstract}

Keywords: Antitrust law, Public policy, Development, Cooperation, Robert axelrod

1 Doutorando em Direito pela Pontifícia Universidade Católica do Paraná - PUC, Paraná, Brasil. É advogado, Professor de Direito Comercial I e II das Faculdades Integradas do Brasil - Unibrasil, Curitiba, Paraná. E-mail: daniel.pastre@gmail.com 


\section{INTRODUÇÃO}

A teoria da cooperação de Robert Axelrod, ao analisar o Dilema do Prisioneiro, torna possível o lançamento de advertências, diretrizes e sugestões de comportamentos que, dentro de um determinado estrato institucional, podem conduzir a uma maior cooperação entre as partes envolvidas em certa relação (em um jogo).

Na tentativa de fazer uma análise concreta da teoria de Robert Axelrod, o estudo avaliará em primeiro momento a própria teoria, suas base (o Dilema do Prisioneiro), suas razões e fundamentos, assim como o ambiente institucional em que promulgada; no segundo capítulo, o objetivo será demonstrar sinteticamente as normas de direito antitruste e as práticas consideradas anticompetitivas, tudo a partir de um ambiente institucional atualizado, reformulando-se a proposição inicial do autor; por fim, o terceiro e último capítulo terá como pressuposto estabelecer os pontos de convergência entre os anteriores, fazendo uma avaliação crítica da doutrina-base e uma releitura da teoria de Robert Axelrod, adaptando-a às instituições nacionais para dizer se o incentivo à cooperação traduz-se igualmente em incentivos à práticas anticompetitivas ou não.

$\mathrm{Na}$ conclusão, espera-se, com o estudo, trazer uma nova óptica para a teoria estudada, uma nova perspectiva que esteja mais próxima ao modelo institucional nacional, verificando se, quando e como a aplicação das advertências, diretrizes e sugestões influencia a cooperação entre sujeitos (na não realização de atos contrários à concorrência) ou, ao revés, conduz à prática de atos anticompetitivos, como a exclusão de competidores do mercado ou a colusão entre eles.

\section{A COOPERAÇÃO EM ROBERT AXELROD}

A primeira parte do artigo objetiva traçar linhas gerais acerca da teoria da cooperação de Robert Axelrod, tratada no livro The Evolution of Cooperation (AXELROD, 1984), a fim de tornar possível uma posterior aplicação da teoria para as condutas anticompetitivas, visando verificar se, quando e como a referida teoria impacta na realização de atos cooperativos ou não, e como podem acarretar um desvio de conduta, induzindo ao ilícito concorrencial, como, por exemplo a formação de cartéis, a possibilidade de dominação de mercados ou a exclusão ilícita de concorrentes.

Mas, antes mesmo de entrar no mérito de como promover ou incrementar a cooperação, o autor avalia diversas estratégias em jogos cooperativos, em situações de 
interação prolongada entre duas partes, como no Dilema do Prisioneiro (base para todo o estudo), para o fim de verificar se há uma estratégia dominante ou uma estratégia que poderia ser utilizada em qualquer situação (se é melhor cooperar, trair ou alterar, por exemplo).

O Dilema do Prisioneiro foi enunciado por Albert William Tucker, descrevendo ele uma situação onde duas pessoas são acusadas de um crime grave, mas a polícia tem provas apenas para incriminá-las por um crime menor, sendo imprescindível a obtenção de uma confissão. As duas são postas em salas de interrogatório separadas, sendo impossível a comunicação. A partir daí, se elas não confessarem somente serão condenadas pelo crime menor; se houver confissão recíproca as partes pegam a pena pelo crime maior, mas com uma redução do valor-base em virtude da confissão; se a acusação for unilateral, uma parte sai livre e a outra pega a pena pelo crime mais grave. Dentre desse contexto, confessar é a estratégia dominante, tendo em vista o livramento (se o outro não confessar) ou a diminuição de pena (se o outro confessar) (RIBEIRO; GALESKI JÚNIOR, 2015, p. 128). Para Robert Axelrod, dentro desse contexto, utilizar a estratégia "olho por olho" é genericamente a melhor, não por ganhar de outras estratégias, mas sim por evitar grandes perdas (AXELROD, 1984, p. 27-54).

A estratégia "olho por olho" é a que tem um robusto sucesso em jogos prolongados, como testado empiricamente por programas de computador, por sua combinação em ser boa, em retaliar, perdoar e ser clara. A característica da bondade previne a estratégia de entrar em (ou causar) problemas desnecessariamente. A retaliação desencoraja a outra parte em persistir na opção de trair. O perdão auxilia a restaurar a mútua cooperação após uma tentativa de traição. E a claridade a torna facilmente reconhecível para a outra parte, acarretando boa compreensão e provocando para diante uma cooperação de longo prazo (AXELROD, 1984, p. 54).

A partir dessa estratégia, são traçadas algumas advertências às partes que se encontrarem em uma situação parecida com o Dilema do Prisioneiro e, posteriormente, são lançadas diretrizes ou sugestões de modificações comportamentais (ou mesmo nas estratégias de cada parte) para incentivar a cooperação. As advertências são claras: não ser invejoso, não ser o primeiro a trair, devolver tanto cooperação como traição na mesma moeda, não ser esperto demais (AXELROD, 1984, p. 110).

A primeira advertência relaciona-se ao fato das pessoas sempre pensarem em jogos de soma zero; ou seja, para a maioria, em todas as interações entre as partes uma delas tem que ganhar e a outra perder. Contudo, a vida não é um jogo de soma zero, ambas as partes 
podem ganhar (ir bem) ou ambas podem perder (ir mal), e o grande problema está na inveja do sucesso alheio.

E um exemplo do autor esclarece bem a questão: se várias pessoas são convidadas a jogar o Dilema do Prisioneiro, ganhando um ponto quando jogarem melhor para si mesmas, após algumas rodadas as comparações de resultados entre os jogadores (e a avaliação da média geral) acabará por incentivar outros a trair, visando conseguir mais pontos. Logo, todos trairão para atingir a média de pontos das partes envolvidas; ou seja, invejar a pontuação alheia, neste caso, serviu de incentivo à traição, não à cooperação, porque trair gera inicialmente uma pontuação maior.

Desta forma, a primeira advertência transmuta-se em não invejar o sucesso alheio e, para isso, é melhor evitar a comparação entre os sucessos e pensar em como o jogador estaria se fosse o outro. Perguntar como o outro jogador está indo não é um bom padrão de comportamento, a não ser que o objetivo seja destruir o jogador. Quando o objetivo não for este, a comparação causa uma inveja destrutiva e deve ser evitada. É melhor, então, questionar acerca do sucesso do jogador se estivesse na pele de outro (ele faria algo diferente ou o sucesso seria o mesmo dentro das mesmas condições) (AXELROD, 1984, p. 110-112).

A segunda advertência diz para não ser o primeiro a trair. As avaliações teóricas e empíricas demonstram que somente vale a pena cooperar enquanto a outra parte também cooperar. Por isso, uma estratégia geral, como a "olho por olho", somente não é aceitável se as partes contrárias nunca cooperarem. Existindo uma cooperação mínima nos jogos testados (cinco por cento ou mais), sempre renderá mais cooperar do que trair; ou seja, se a probabilidade de existirem indivíduos que cooperem é grande, trair é ineficiente e cooperar sempre produzirá resultados melhores (AXELROD, 1984, p. 113-117).

A terceira advertência está relacionada à reciprocidade, em devolver tanto cooperação como traição na mesma moeda. Isso quer dizer que a parte sempre iniciará cooperando e, após, replicará a atuação da outra: existindo cooperação, mantém-se a cooperação; havendo traição, altera-se para traição, e assim por diante. A advertência torna possível uma cooperação inicial e evita perdas futuras com o excesso de expectativa (o excesso de cooperação ou de perdão por traições) (AXELROD, 1984, p. 118-120).

A última advertência é não ser esperto demais. Nas interações entre as partes regras sofisticadas de comportamento não são melhores do que as simples. As regras que tentam maximizar o seu próprio ganho tratam a outra parte como algo inerte, ignorando o aspecto da interação e os resultados de seu próprio comportamento. Desta forma, esquecem-se dos ecos 
ou reverberações do processo de interação e do fato de que a outra parte está se adaptando ao comportamento do avaliador a cada novo lance.

Na síntese, a cooperação não exige algo além da própria cooperação. Ao contrário de jogos de soma zero, onde a dúvida sobre a cooperação (ou sobre a estratégia do oponente) torna a jogada do outro ineficiente, melhorando a situação do primeiro jogador, em jogos cooperativos o melhor é ser claro quanto à possibilidade de cooperação, evitando regras complexas ou evitando deixar o outro jogador em dúvida sobre a reciprocidade da cooperação (AXELROD, 1984, p. 120-123).

Para promover a cooperação, as modificações comportamentais citadas pelo autor variam entre aumentar a importância do futuro, modificar a proporção das recompensas, trabalhar a alteridade, a reciprocidade ou a capacidade de reconhecimento das partes, pontos conectados diretamente às advertências iniciais, como visto.

O primeiro item diz respeito a importância do futuro ou o incremento da sombra do futuro. A cooperação, neste caso, somente pode tornar-se estável se o futuro tem uma importância relativa maior do que o presente. Dito de outro modo, se existe alta probabilidade de a interação terminar após poucas rodadas e/ou se há preferência em colher os benefícios dela imediatamente ao invés de aguardar o deslinde das jogadas, é preferível adotar outra tática, como sempre trair ou alternar entre trair e cooperar. Promover a cooperação a partir daí significa, portanto, tornar as interações entre as partes mais duráveis e mais frequentes. Para isso, é possível diminuir as distantes das jogadas (tornar a relação das partes mais frequente), afastar diretamente outros competidores (o que voltaria a atenção apenas aos jogadores em questão) e diluir os benefícios, promovendo maior estabilidade e forçando a durabilidade da relação (AXELROD, 1984, p. 126-132).

A outra forma de incrementar a cooperação é aumentar os benefícios ou as recompensas para os envolvidos. A estabilidade de um sistema de cooperação está relacionada aos sistemas de recompensa (ao sistema de benefícios e riscos, pesos e contrapesos), assim, alterando-se a recompensa (ou diminuindo-se os riscos) com incentivos para a cooperação, esta, sendo o incentivo de curto prazo menor do que o de longo prazo, naturalmente ocorrerá. Para dizer de forma diversa, se os incentivos para a cooperação mútua forem maiores que os benefícios da traição, as partes, no longo prazo, manterão o padrão cooperativo com benefícios recíprocos (AXELROD, 1984, p. 133).

A terceira diretriz para promover a cooperação é ensinar as pessoas a se importar umas com as outras, cientes da dificuldade inerente à necessidade de moldar esses valores (da alteridade e do altruísmo) desde os mais novos cidadãos, fazendo-os preocupados não apenas 
com o seu bem-estar, mas também e principalmente com o dos outros. Isso não significa que pessoas egoístas devam receber o mesmo tratamento daquelas dispostas a cooperar. As partes que exploram a cooperação das demais (que traem para benefício próprio, a fim de manter a perspectiva do Dilema do Prisioneiro) merecerem tratamento diverso do dispensado àquelas que nutrem o mesmo sentimento de altruísmo, até porque isso as levará à cooperação, repensando a estratégia inicial (AXELROD, 1984, p. 134).

Uma quarta forma é ensinar a reciprocidade. É possível pensar que a estratégia "olho por olho" seja a melhor individualmente, mas talvez não funcione em ampla escala ou no seio da sociedade. Para testar isso, é preciso reconhecer que há um padrão moral, uma regra de outro, que diz "faça com aos outros o que gostaria que fizessem com você". Em um jogo ao estilo Dilema do Prisioneiro, atuar sempre da mesma forma (com cooperação incondicional, porque é isso que se espera dos outros) acarreta a exploração de uma pessoa por outra, deixando um fardo à comunidade em geral que sugere que a tese da reciprocidade, o "olho por olho", é melhor que o sistema de cooperação incondicional. Parece ser mais benéfico para o coletivo, então, um sistema lastreado na regra "olho por olho" e também em reciprocidade, porque, além de incentivar a cooperação entre as partes, promove a fiscalização pela coletividade (e a comunidade punirá aqueles com condutas que desviem desse padrão aceitável), fortalecendo o próprio sistema (AXELROD, 1984, p. 136-139).

Por fim, a última alternativa que beneficia o sistema cooperativo é a melhora das capacidades de reconhecimento do outro e de suas jogadas, porque saber se o outro vai ou não cooperar (ou se vai trair esperando uma maior recompensa), compreender suas expectativas e suas intenções é a melhor forma de evitar o abuso na ausência de cooperação e de prolongar as jogadas, aumentando a interação e, consequentemente, também a cooperação recíproca (AXELROD, 1984, p. 139-141).

\section{O DIREITO ANTITRUSTE, AS CONDUTAS ANTICOMPETITIVAS E O AMBIENTE INSTITUCIONAL}

Na sequiência do estudo, a fim de possibilitar a posterior conexão entre cooperação e condutas anticompetitivas, optou-se por relacionar sinteticamente os objetivos e fundamentos da legislação antitruste, assim como as possíveis condutas que possam macular a atual norma concorrencial, a partir de um determinado quadro institucional (de uma estrutura de incentivos à cooperação ou traição), reavaliando, a partir deste, o Dilema do Prisioneiro, para que ele possa ser utilizado no próximo capítulo para justificar as proposições iniciais. 


\subsection{O Direito Antitruste e as Condutas Anticompetitivas}

O direito antitruste, para a doutrina nacional, traduz-se pelo conjunto de regras jurídicas que tem como objetivo tornar possível a correta apuração, a repressão e também a prevenção de eventuais abusos de poder econômicos, em todas as suas modalidades (condutas e estruturas), visando igualmente impedir a monopolização de mercados (ou a atuação empresarial que tenha o mesmo efeito da monopolização, como a cartelização), a fim de favorecer a livre iniciativa (e, portanto, também a livre concorrência) em prol de toda a coletividade (OLIVEIRA; RODAS, 2004, p. 29).

E esse quadro institucional existe para assegurar eficiência e bem-estar social, a partir de estruturas descentralizadas e fragmentadas (PINHEIRO; SADDI, 2006, p. 356), avaliadas dentro dessa perspectiva as funções repressivas e preventivas das instituições (especialmente as formais) (SZMID, 2011, p. 299), sem obstar que uma parte da doutrina mantém no centro o papel do bem-estar dos consumidores (BORK, 1978, p. 405). É possível dizer, portanto, que a concorrência tem um papel instrumental, é um meio de incrementar o bem-estar da sociedade, atendendo princípios constitucionais, como a busca pelo desenvolvimento nacional (BAGNOLI, 2005, p. 111).

Para tornar possível essa máxima, a legislação, os princípios e as autoridades competentes têm o papel de educar, prevenir, fiscalizar e repreender condutas incompatíveis com essas premissas, tanto do particular como dos entes públicos (PINTO JÚNIOR, 2005, p. 179). Daí importante a avaliação sobre essas condutas, especialmente para tornar possível o confronto posterior com a teoria apresentada.

A doutrina brasileira separa as condutas anticompetitivas em condutas que visam a exclusão ilícita de concorrentes e condutas que objetivam a colusão entre os concorrentes, ou ainda entre condutas verticais ou horizontais (PINHEIRO; SADDI, 2006, p. 373). Para a exclusão ilícita de concorrentes duas são as condutas típicas, a predação e a negociação compulsória; para a colusão, a classificação restringe-se a condutas verticais (entre não concorrentes diretos) e horizontais (entre concorrentes diretos, gerando a cartelização) (SALOMÃO FILHO, 2003, p. 156).

A predação é um ato pelo qual um agente econômico suporta um prejuízo inicial porque tem a expectativa real de eliminar um concorrente do mercado relevante e, ainda, após a eliminação do dito concorrente, espera ter lucros superiores, seja pelo aumento de preços ou outra forma direta ou indireta de exploração da posição de domínio de mercado agora exercida (SALOMÃO FILHO, 2003, p. 159). Neste caso, há tentativa de exclusão ilícita de 
um dos concorrentes pela venda de preço abaixo do preço de mercado e, por vezes, abaixo do próprio custo de produção do produto, além de um objetivo de açambarcar a clientela do concorrente, eliminado-o, aumentando a concentração e o poder de mercado.

A negociação compulsória, por outro lado, está relacionada ao abuso de posição dominante, quando uma das partes tem poder suficiente para determinar as condições do negócio a ser realizada para a outra e esta não tem alternativa que não conformar-se. Os exemplos clássicos de negociação compulsória envolvem venda casada, recusa de contratar e a elaboração de cláusulas de exclusividade (SALOMÃO FILHO, 2003, p. 198).

A colusão dá-se por acordos verticais, aqueles celebrados entre partes que se situam em uma mesma cadeia produtiva ou de distribuição (a montante ou a jusante) (FORGIONI, 2007, p. 21) ou horizontais, aqueles que são realizados por agente econômicos que concorrem em um mesmo mercado, onde existe concorrência direta (FORGIONI, 2008, p. 395).

Por último, a eliminação direta de um competidor ou a colusão entre eles pode gerar a cartelização, que representa uma restrição ou até mesmo a eliminação direta de concorrência entre um conjunto de atores econômicos com a finalidade de auferir vantagens ilícitas, como aumentar seus lucros. Uma estrutura de ofertas é criada, fixada e coordenada por um ou mais integrantes do cartel, visando conseguir uma precificação uniforme (maior do que o padrão), aproximando-se a colusão horizontal à monopolização do mercado em que atuar (o mercado relevante) (GABAN, 2009, p. 165).

\subsection{O Ambiente Institucional e o Dilema do Prisioneiro Inverso}

A avaliação sobre a possibilidade de cooperação depende do próprio ambiente institucional em que realizada, porque, passando por Ronald Coase, uma vez que existem custos de transação e a partir da existência de racionalidade limitada, o arranjo institucional efetivamente fará a diferença nas estratégias dos indivíduos.

É por isso que Douglas North diz que as instituições são formadas a partir de restrições formais (leis, regras, etc) ou informais (usos e costumes, por exemplo). São elas que definem a estrutura de incentivos em uma sociedade. Dito de outro modo, em um ambiente onde existem custos de transação, os jogadores, agindo racionalmente, tendem a maximizar seus ganhos com base nas informações obtidas e no erro e acerto ao longo do tempo, e o papel das instituições seria o de guiar os jogadores em direção as informações necessárias para o arranjo social mais eficiente (para a coletividade); porém, as instituições acabam por servir a interesses daqueles que tem poder de barganha para criar novas regras ou aproveitar de suas 
brechas, sendo a ineficiência econômica e política uma regra, e a eficiência uma exceção (NORTH, 1994, p. 360).

A simbiose entre as instituições (as regras, por exemplo) e as organizações (os empresários ou grupos de pessoas reunidas em outro modelo) é que moldam a evolução de uma economia e que ditam a forma tomada pelo mercado; no caso, se as instituições dão as regras do jogo, pode-se considerar que as organizações são os jogadores. Assim, se as instituições incentivam o ilícito, as organizações criminosas surgirão; se as instituições incentivam atividades educacionais, então mais organizações educacionais surgirão, e assim por diante (NORTH, 1994, p. 361-362).

Por isso, um ponto crucial para a correlação proposta no artigo diz respeito ao fato de que a lógica da exclusão da concorrência e da colusão entre concorrentes acaba gerando uma estrutura de incentivos (um arranjo institucional) diversa da avaliada no Dilema do Prisioneiro, ao menos em relação as estruturas de incentivo à cooperação e/ou traição atuais, traduzida como incentivo à prática de atos contra a concorrência e a favor dela. E prova disso são inúmeros esquemas descobertos atualmente, como as fraudes em licitações, a cartelização, os desvios de valores do Estado e outros, todos noticiados em bases diárias.

Ao que parece, a partir dos exemplos, as pessoas acabam desestimuladas a cooperar (a cumprir a lei e não praticar ilícitos, por exemplo), quando percebem que outras não cooperar (traem e praticam diversos ilícitos) e obtém vantagens manifestas e das mais variadas formas (LUCON, 2008, p. 366). Há um universo de sobreintegrados, nas palavras de Marcelo Neves, que poderão orientar suas condutas com a ciência plena, uma quase certeza, de que não serão responsabilizados ou punidos por suas ações (NEVES, 2008, p. 255). Desta forma, um quadro realista da situação envolvendo uma conduta anticompetitiva dentro do modelo institucional brasileiro seria semelhante ao abaixo:

\begin{tabular}{|c|cc|}
\hline \multirow{2}{*}{ AC̣ÃO } & $\begin{array}{c}\text { PARTE 2 NÃO PARTICIPA } \\
\text { DO ILÍCITO }\end{array}$ & $\begin{array}{c}\text { PARTE 2 PARTICIPA DO } \\
\text { ILÍCITO }\end{array}$ \\
\hline $\begin{array}{c}\text { PARTE 1 NÃO PARTICIPA } \\
\text { DO ILÍCITO } \\
\text { PARTE 1 PARTICIPA DO } \\
\text { ILÍCITO }\end{array}$ & 1,1 & 0,5 \\
\cline { 2 - 3 } & 5,0 & 3,3 \\
\hline
\end{tabular}

Fonte: elaboração do autor. 
No quadro acima, tem-se que as partes podem cooperar (não realizando condutas anticoncorrenciais, atuando no mercado estritamente conforme as regras do jogo) recebendo uma recompensa mútua de 1 ponto. Uma delas poderia trair a outra (realizando a conduta anticompetitiva) e receber 5 pontos, deixando nada para quem cooperou (não praticou as referidas condutas) e, por fim, ambas podem participar ativamente dos ilícitos concorrenciais e, assim, lucrar mais do que não participando, mas não tanto quanto se a outra não participasse. A estrutura de incentivos à cooperação, como dito, tem uma base equivocada.

Pela exposição, é possível dizer que o Dilema do Prisioneiro inverso retrata o atual quadro institucional, as atuais estruturas e organizações que incentivam (ou não) a prática de atos de cooperação ou atos contrários à cooperação, como a exclusão e a colusão, prática consideradas anticoncorrenciais. Portanto, compete agora aplicar a teoria de Robert Axelrod dentro desse panorama, verificando-se os resultados.

\section{A TEORIA DA COOPERAÇÃO E A PRÁTICA DE ILÍCITOS CONCORRENCIAIS}

A finalização do artigo demanda, agora, a correlação entre a teoria da cooperação de Robert Axelrod e a forma como as advertências e as diretrizes para promover a cooperação, dentro desse novo espectro institucional (da reavaliação das estruturas), podem acarretar a realização de condutas ilícitas e consideradas pela doutrina da concorrência como anticompetitivas, maculando a livre iniciativa (e também a livre concorrência), com danos ao sistema de mercado.

A começar pelas advertências, como dito anteriormente, são destacadas as seguintes lições: não ser invejoso, não ser o primeiro a trair, devolver tanto cooperação como traição na mesma moeda, não ser esperto demais (AXELROD, 1984, p. 110). Todas as advertências podem acarretar efeitos anticoncorrenciais, seja por direcionar os competidores à exclusão ilícita de outros concorrentes, seja por levá-los à colusão ou por incentivar a mesma através de acordos verticais ou horizontais.

A advertência inicial para não ser invejoso pode, sob certas circunstâncias, tanto promover a cooperação inclusiva como exclusiva. Explica-se: supondo que dois empresários atuem em uma cadeia de produção, um vendendo matéria prima e outro comprando-a para transformação e venda ao mercado. É de se esperar que um relacionamento contínuo possa gerar benefícios mútuos (lucro), sendo desnecessária a realização de atos invejosos, aqui traduzidos como qualquer tentativa de retaliação (não pagamento de contas, por exemplo), posto que acarretará um outro ato invejoso, a partir de uma estratégia "olho por olho". Isso 
quer dizer que quando presente a inveja do fornecedor ou comprador ninguém vende e ninguém lucra com a transformação da mercadoria, arcando àquele que inicialmente cooperou com um prejuízo mínimo relativo a primeira jogada da interação (o fornecimento inicial da matéria prima sem a devida contraprestação). Neste caso há inclusão, benefício, e a ausência de inveja promove a cooperação com reflexos positivos para a coletividade.

Contudo, em um jogo complexo, onde muitos vendedores e compradores atuam e, do mesmo modo, onde está presente uma prática ilícita, como o cartel entre alguns ou todos os vendedores, a ausência de inveja acarreta a manutenção do acordo, fortalecendo-o. Isso, porque a inveja relaciona-se não ao lucro do vizinho (ou do companheiro de cartel), mas sim a avaliação do todo, incluindo aqueles que não participam do cartel (AXELROD, 1984, p. 111); ou seja, ao passo em que trair os demais concorrentes (cartelizar) gera um benefício imediato (lucro maior), a manutenção do cartel é incentivada porque os seus membros estarão em situação melhor do que outros que dele não participam e que, por conseguinte, continuam cooperando (não cartelizando).

Uma solução para o caso seria seguir a segunda advertência, de manter a estratégia "olho por olho". Isso supostamente evitaria que todos os concorrentes participassem da estrutura cartelizada, posto que nos exemplos a cooperação (a não cartelização) é sempre superior a traição (a cartelização) (AXELROD, 1984, p. 8). Contudo, uma vez instaurado o cartel, a estratégia anterior induziria os demais concorrentes ao esquema, sob pena de ficar configurado um jogo onde uma parte sempre trai (formando o cartel) e outra sempre cooperada (não faz parte do cartel), o que gerará lucros exorbitantes aos cartelizados e prejuízos terríveis ao não cartelizados.

Isso acaba, do mesmo modo, com a terceira, quarta e quinta advertências, no sentido de não ser o primeiro a trair (no caso, participar do cartel ou praticar atos anticompetitivos), de desenvolver sempre a estratégia "olho por olho" (significando a indução ao cartel em caso de prejuízo pela não participação) e de não ser esperto demais (porque neste caso, não ser esperto demais é acabar utilizando a estratégia anterior, o que desembocará ao final em estruturas cartelizadas).

Para promover a cooperação (um mercado competitivo, portanto), as modificações comportamentais citadas pelo autor variam entre aumentar a importância do futuro, modificar a proporção das recompensas, trabalhar a alteridade, a reciprocidade ou a capacidade de reconhecimento das partes. Porém, tal como as advertências, o incentivo à cooperação, para alguns casos, por manter a estrutura desviada de comportamentos e inclusive incentivá-la, incrementando-a. 
Ora, para aumentar a importância do futuro as partes podem realizar interações mais frequentes, afastar a concorrência e dar estabilidade à relação (com a distribuição dos lucros em pequenas doses), e isso justifica a exclusão de concorrentes ou a criação de mecanismos artificiais para afastamento da concorrência, especialmente barreias à entrada de novos competidores (AXELROD, 1984, p. 130). Há, aqui, um incentivo a um ilícito concorrencial expresso no artigo 36, $§ 3 .^{\circ}$, III, IV e V, da Lei Antitruste. ${ }^{1}$

$\mathrm{Na}$ seqüência, tem-se que uma das importantes formas é trabalhar a cooperação é alterar a estrutura de incentivos, especialmente os legais (as instituições formais), para a realização de determinadas condutas, induzindo as partes à cooperação (e não ao excesso de cooperação que pode gerar uma prática desleal); ou seja, a partir do quadro anterior (Dilema do Prisioneiro inverso), é preciso diminuir os lucros por trair (por praticar condutas anticompetitivas) e aumentar os benefícios por cooperar (não praticar condutas contra a concorrência, mantendo o padrão de mercado), tendo em vista que os agentes econômicos, com base em comportamento oportunista, buscam a próprio interesse ainda que por condutas ilícitas. Só há respeito a regra do jogo se convier ao mesmo e, portanto, para que seja conveniente a cooperação, e não a realização de condutas contra a concorrência, imprescindível mudanças estruturais, mudanças ns instituições formais e informais, como dito (PINHEIRO; SADDI, 2006, p. 63-65).

\footnotetext{
${ }^{1}$ Art. 36. Constituem infração da ordem econômica, independentemente de culpa, os atos sob qualquer forma manifestados, que tenham por objeto ou possam produzir os seguintes efeitos, ainda que não sejam alcançados: (...)

$\S 3^{\mathrm{o}}$ As seguintes condutas, além de outras, na medida em que configurem hipótese prevista no caput deste artigo e seus incisos, caracterizam infração da ordem econômica:

(...)

III - limitar ou impedir o acesso de novas empresas ao mercado;

IV - criar dificuldades à constituição, ao funcionamento ou ao desenvolvimento de empresa concorrente ou de fornecedor, adquirente ou financiador de bens ou serviços;

$\mathrm{V}$ - impedir o acesso de concorrente às fontes de insumo, matérias-primas, equipamentos ou tecnologia, bem como aos canais de distribuição;
} 
Note-se que o artigo 37, I, II e II, da Lei Antitruste, ${ }^{2}$ e o $\operatorname{artigo} 4 .^{\circ}$ da Lei $8.137 / 1990,{ }^{3}$ estabelecem para condutas anticoncorrenciais multas para as pessoas envolvidas, variando entre $0,1 \%$ (um décimo por cento) até $20,0 \%$ (vinte por cento) do faturamento bruto do ano anterior à instauração do procedimento administrativo, para as pessoas jurídicas, e $1,0 \%$ (um por cento) a 20,0\% (vinte por cento) da anterior aos administradores, diretores e gerentes; ainda, podem ser aplicadas sanções criminais que variam de dois a cinco anos de reclusão e multa.

A partir do quadro modificado do Dilema do Prisioneiro e alterando o sistema de pontos por milhões de reais, tem-se que, se um acordo ilícito entre dois empresários, dentro de um universo de outros dez competidores, durar apenas uma rodada (o que pode ser traduzido por um ano, a título de exemplo), os seus lucros com o ilícito serão trezes vezes maiores que daqueles que não participam do esquema, sendo seus prejuízos calculados em no máximo $20,0 \%$ ou $\mathrm{R} \$ 600.000,00$ e, sendo o administrador, diretor ou gerente condenado, o máximo da condenação será o equivalente a outros $\mathrm{R} \$$ 120.000,00. A partir daí, em rodada única, aquele que participa do ilícito e é autuado administrativamente tem um lucro líquido de R\$ 2.280.000,00 e quem não participa tem o lucro basilar de $\mathrm{R} \$ 1.000 .000,00$. E, quanto mais rodadas (quando maior o prazo da interação), menor é proporcionalmente a pena, já que ela é calculada com base apenas no último exercício da instauração do procedimento administrativo.

Há incentivo direto à prática desleal (e prática desleal prolongada no tempo, porque quanto maior o tempo mais diluída a sanção correspondente), que somente poderia ser

\footnotetext{
${ }^{2}$ Art. 37. A prática de infração da ordem econômica sujeita os responsáveis às seguintes penas:

I - no caso de empresa, multa de $0,1 \%$ (um décimo por cento) a $20 \%$ (vinte por cento) do valor do faturamento bruto da empresa, grupo ou conglomerado obtido, no último exercício anterior à instauração do processo administrativo, no ramo de atividade empresarial em que ocorreu a infração, a qual nunca será inferior à vantagem auferida, quando for possível sua estimação;

II - no caso das demais pessoas físicas ou jurídicas de direito público ou privado, bem como quaisquer associações de entidades ou pessoas constituídas de fato ou de direito, ainda que temporariamente, com ou sem personalidade jurídica, que não exerçam atividade empresarial, não sendo possível utilizar-se o critério do valor do faturamento bruto, a multa será entre $\mathrm{R} \$$ 50.000,00 (cinquenta mil reais) e R \$ 2.000.000.000,00 (dois bilhões de reais);

III - no caso de administrador, direta ou indiretamente responsável pela infração cometida, quando comprovada a sua culpa ou dolo, multa de $1 \%$ (um por cento) a $20 \%$ (vinte por cento) daquela aplicada à empresa, no caso previsto no inciso I do caput deste artigo, ou às pessoas jurídicas ou entidades, nos casos previstos no inciso II do caput deste artigo.

${ }^{3}$ Art. $4^{\circ}$ Constitui crime contra a ordem econômica:

I - abusar do poder econômico, dominando o mercado ou eliminando, total ou parcialmente, a concorrência mediante qualquer forma de ajuste ou acordo de empresas;

II - formar acordo, convênio, ajuste ou aliança entre ofertantes, visando:

a) à fixação artificial de preços ou quantidades vendidas ou produzidas;

b) ao controle regionalizado do mercado por empresa ou grupo de empresas;

c) ao controle, em detrimento da concorrência, de rede de distribuição ou de fornecedores.

Pena - reclusão, de 2 (dois) a 5 (cinco) anos e multa.
} 
remediada com a alteração da estrutura de incentivos (alteração nas instituições formais), aumentando as sanções proporcionalmente ao tempo da conduta, por exemplo, ou estabelecendo as multas em valor suficiente a indenizar todos os prejuízos causados (OLIVEIRA; RODAS, 2004, p. 344). As penas pecuniárias, caso equivalentes ao montante do lucro pela prática ilícita, tornariam no mínimo equivalentes os benefícios por cooperar ou não (3 e 3 transmutam-se em 1 e 1), fato que, somando aos prejuízos e desgastes relacionados ao processo, os custos com a defesa, os prejuízos à imagem empresarial e outros, tornariam melhor cooperar (não praticar ilícitos) a trair (praticá-los).

Para tornar mais factível a explanação, pode ser observada a ementa do seguinte procedimento junto ao Conselho Administrativo de Defesa Econômica:

O Tribunal, por unanimidade, em preliminar, excluiu do polo passivo do Processo Administrativo os Postos Grazziotin. No mérito, por unanimidade, considerou a conduta do Sindicato do Comércio Varejista de Derivados de Petróleo de Santa Catarina (Sindipetro/SC) subsumida aos artigos 20, I, II e III e artigo 21, II, todos da Lei 8884/94, aplicando multa pecuniária no valor de $\mathrm{R} \$ 55.000,00$ (cinqüenta e cinco mil reais), consoante o artigo 23, III, da Lei 8884/94. Em relação aos demais postos representados (A Roleta Auto Posto Ltda., Posto Central, Posto de Combustíveis Dematé, Posto D. Pedro, Posto Marechal, Auto Raid, Posto Lageano, Posto Rex Ltda., Auto Posto Ouro Preto Ltda.), o Plenário os considerou incursos nas práticas dos artigos 20, I, II e III e 21, I e XXIV da Lei 8884/94 e, nos termos do artigo 23, I, da mesma Lei, e determinou a aplicação de multa pecuniária no valor equivalente a $15 \%$ de seu faturamento anual nos termos do voto do Relator. Quanto às pessoas físicas representadas (Osmar Dematé, Fernando Picini, Álvaro Mondadore Júnior, Valmor Medeiros Júnior, José Antônio Granzotto Neves, Guido José Moretto, Pedro Fernandes Júnior, Jorge Córdova, Sado Montemezzo), o Tribunal considerou suas condutas subsumidas aos artigos 20, I, II e III e 21, I e XXIV e, nos termos do artigo 23, II da Lei 8884/94, aplicou multa pecuniária para cada pessoa física em $15 \%$ do quantum da multa imposta à empresa na qual participe como sócio gerente, controlador ou responsável legal, e que tenha sido apenada nesse processo. Ademais, determinou o Plenário a publicação de extrato da decisão em meia página e à dispensa do infrator, em jornal diário de maior circulação em Lages/SC, por dois dias consecutivos no prazo de 30 (trinta) dias contados a partir da publicação do acórdão do Tribunal, assim como a inscrição das pessoas jurídicas e físicas representadas, no Cadastro Nacional de Defesa do Consumidor, consoante o artigo 24, III, da Lei 8884/94 e também multa diária de $\mathrm{R} \$$

$6.000,00$ (seis mil reais) pelo não cumprimento das sanções aplicadas (BRASIL, Conselho Administrativo de Defesa Econômica, 2001).

As multas aplicadas equivaliam a 229,16 salários mínimos para o Sindicato acusado de cartelização, além de $15 \%$ desse valor para as pessoas físicas e $15 \%$ do faturamento de cada pessoa jurídica (referente ao exercício anterior à data da instauração do procedimento administrativo). Para hoje, os valores seriam próximos de $\mathrm{R} \$ 180.578,08$ e frações desse valor para as demais pessoas. Posta a premissa, se o faturamento bruto anual dos cartelizados é o triplo dos não cartelizados (ou do mercado em geral) em uma rodada (um exercício), se a multa (pela legislação anterior) era equivalente ao máximo de 30,0\% daquele faturamento (na 
legislação atual a multa foi reduzida a 20,0\%), é crível dizer que o faturamento bruto anual dos cartelizados na época era de atuais $\mathrm{R} \$ 601.926,95$, que descontada a multa resulta em $\mathrm{R} \$$ $421.348,87$, quantia superior ao faturamento presumível dos não cartelizados, atuais R\$ 200.642,32 (um terço dos cartelizados). Assim, há interesse no arranjo ilícito e incentivo real a sua realização, portanto. E, como dito, sendo a multa reduzida na legislação atual, a alteração na estrutura de cooperação (não realização de condutas ilícitas) foi reversa e, consequentemente, a colusão está ainda mais benéfica à realização da prática desleal.

E o mesmo vale na seara penal, onde, para além da branda sanção, a dificuldade da prospecção de provas e na realização da própria denúncia (que deve detalhar os crimes econômicos) podem por vezes geram uma situação de risco zero, especialmente para sócios, administradores, diretores e gerentes. Assim, a estrutura que conduz aos agentes à prática de atos ilícitos é fortalecida. A título de exemplo, o seguinte julgado do Superior Tribunal de Justiça:

"PROCESSUAL PENAL. HABEAS-CORPUS. AÇÃO PENAL. CRIME CONTRA AS RELAÇÕES DE CONSUMO (LEI No 8.137, ART. 5, II). DENÚNCIA INEPTA. TRANCAMENTO.

- A denúncia deve conter a exposição do fato criminoso, com todas as suas circunstâncias (CPP, art. 41), com adequada indicação da conduta ilícita imputada ao réu, de modo a propiciar-lhe o pleno exercício do direito de defesa, uma das mais importantes franquias constitucionais.

- Contém a mácula da inépcia a denúncia que formula acusação genérica de prática de crime contra as relações de consumo, sem apontar de modo circunstanciado a participação dos réus no fato delituoso.

- A mera qualidade de sócio ou diretor de uma empresa, na qual se constatou a ocorrência de crime no processo de venda, não autoriza que contra o mesmo diretor seja formulada uma acusação penal em Juízo...” (BRASIL, Superior Tribunal de Justiça, 1999).

$\mathrm{Na}$ sequência, outras diretrizes foram tratadas como práticas que incentivam a cooperação, dentre elas, o tratamento diferenciado daqueles que traem, a reciprocidade (que garante uma suposta autofiscalização) e a capacidade de reconhecimento das jogadas (AXELROD, 1984, p. 136-141). Nenhuma dessas práticas é capaz de alterar a estrutura de incentivos à práticas anticompetitivas dentro do atual quadro institucional. $\mathrm{O}$ tratamento diferenciado sofre com o mesmo problema da estratégia "olho por olho", tendo em vista o incentivo direto ao ilícito que vigora atualmente; ou seja, a adoção da estratégia "olho por olho" somente funcionaria a partir da alteração inicial da estrutura de incentivos (onde trair tenha recompensa final inferior a cooperar ou no mínimo igual), porque do contrário não cooperar compensará. 
As demais, ao contrário do que possa parecer, igualmente fortalecem a estrutura de exclusão e colusão, porque ao passo em que determinam um alto poder de fiscalização ou de policiamento recíprocos, que pode fazer com que traidores (que praticam atos anticoncorrenciais) sejam denunciados e desencorajados (AXELROD, 1984, p. 138) ou que possam favorecer o altruísmo ou alteridade, o sentimento de pertencimento e de identificação com o próximo (RORTY, 2007, p. 316), ou ainda que possam incrementar a conexão a determinada comunidade ou nação (o que daria suporte moral e incentivaria o comportamento cooperativo) (ROSS, 2003, p. 413), ou por fim o conhecimento sobre as próximas jogadas (diminuição da racionalidade limitada), também o fazem em relação ao grupo criminoso, ao companheiros de cartel, por exemplo.

É possível se argumentar, portanto, que em um caso de colusão (ou mesmo colusão para fomentar a exclusão de concorrente e dominação de mercados), aumentar a fiscalização pode ser interpretada também como incentivo ao grupo para criar artifícios internos de controle, como uma entidade fiscalizadora, fato ocorrido nos primeiros casos de trust nos Estados Unidos (onde vários empresários passavam o controle a um ou a uma entidade central a fim de falsear os preços, lucrando indevidamente através da figura do trustee) (SALOMÃO NETO, 1996). E a prova disso está relacionada aos casos examinados, onde os Sindicatos agiam como essa entidade centralizadora de poder e comando.

No mesmo sentido, o reconhecimento do próximo, o suporte moral ou o conhecimento mais profundos sobre as interações (sobre as próximas jogadas), aplicado ao atual panorama institucional (que incentiva a traição), atraem pessoas ao cometimento de ilícitos concorrenciais, ao agir não cooperativo, porque fortalecem as relações entre os próprios agentes que praticam os atos exclusivos ou colusivos. Isso quer dizer que aqueles reunidos para lucros ilícitos derivados de uma posição dominante, por exemplo, porque podem se fiscalizar melhor, conhecer melhor as jogadas a partir de instituições fracas (que conduzem ao ilícito), conduzem seus comportamentos, direcionando-os inclusive para a manutenção de atividades ilícitas mais eficientes economicamente (com menos perdas).

Pelo exposto, as advertências e sugestões de Robert Axelrod funcionam bem em um modelo com instituições fortes, com boas estrutura de incentivo à cooperação; no atual panorama brasileiro, o modelo é incompatível e transmuta-se, para o bem da verdade, em advertências e sugestões para incrementar e promover práticas anticoncorrenciais, como o comportamento exclusivo e/ou colusivo, tornando imprescindível uma reavaliação das próprias instituições formais e informais para que a cooperação possa ser incentivada, com sugerido anteriormente. 


\section{CONCLUSÃO}

A proposta do presente artigo foi fazer uma avaliação da teoria da cooperação de Robert Axelrod, relacionando-a, a partir de determinado modelo institucional (ainda que revisado posteriormente), com as práticas anticoncorrenciais, buscando analisar a aplicação da teoria ao modelo institucional atual (as estruturas de incentivos) e suas consequências.

Nos capítulos iniciais, esclareceu-se a respeito do Dilema do Prisioneiro, e as advertências comportamentais feitas por Robert Axelrod, tais como não ser invejoso, não ser o primeiro a trair, devolver tanto cooperação como traição na mesma moeda, não ser esperto demais. Do mesmo modo, foram apresentadas formas de promover a cooperação, como aumentar a importância do futuro, modificar a proporção das recompensas (dos incentivos para cooperação), trabalhar a alteridade, a reciprocidade ou a capacidade de reconhecimento das partes.

Essas advertências e sugestões, como visto no capítulo seguinte, tomam por base um modelo institucional incompatível com a realidade brasileira. Daí, considerando-se que o comportamento exclusivo ou colusivo é incentivado no atual quadro de estruturas de incentivo (ou não) a comportamentos cooperativos, propôs-se uma reavaliação do Dilema do Prisioneiro, o que gerou a inversão dos valores para os comportamentos de cooperar e trair e, portanto, incremento da probabilidade de traição (que geram e mantém as práticas anticompetitivas).

Por fim, sob essa perspectiva, a avaliação final é de que a teoria de Robert Axelrod, quando aplicada em um ambiente com instituições fracas, especialmente as formais (como a estrutura normativa brasileira), e onde o Dilema do Prisioneiro pode e deve ser reestruturado, acarreta um efeito contrário ao esperado inicialmente, gerando e incentivando comportamentos egoístas e de traição (prática de atos anticompetitivos), ao revés do almejado comportamento cooperativo, base da obra do autor.

\section{REFERÊNCIAS}

AXELROD, Robert. The Evolution of Cooperation. New York: Basic Books Inc. Publisher, 1984

BAGNOLI, Vicente. Introdução ao Direito da Concorrência: Brasil, Globalização, União Européia, Mercosul, ALCA. São Paulo: Editora Singular, 2005 
BORK, Robert Heron. The Antitrust Paradox: a policy at war with itself. New York: The Free Press, 1978

BRASIL. Conselho Administrativo de Defesa Econômica. Processo Administrativo 08012.004036/2001-24. Representação com vistas a apurar suspeita de formação de cartel entre as empresas revendedoras de combustíveis no município de Lajes/SC, sob a influência do Sindicato do Comércio Varejista de Derivados de petróleo (SINDIPETRO/SC). Conselheiro Relator: Thompson Almeida Andrade. Julgamento em 23/07/2003. Disponível em: <www.cade.gov.br> Acesso em: 27 jul. 2015

BRASIL. Lei 12.529 de 2011. Estrutura o Sistema Brasileiro de Defesa da Concorrência; dispõe sobre a prevenção e repressão às infrações contra a ordem econômica; altera a Lei $\mathrm{n}^{\text {o }}$ 8.137, de 27 de dezembro de 1990, o Decreto-Lei n-3.689, de 3 de outubro de 1941 - Código de Processo Penal, e a Lei n- 7.347, de 24 de julho de 1985; revoga dispositivos da Lei n8.884, de 11 de junho de 1994, e a Lei no 9.781, de 19 de janeiro de 1999; e dá outras providências. Diário Oficial de União. Poder Legislativo. Brasília, DF, 01 dez. 2011, p. 1

BRASIL. Lei 8.137 de 1990. Define crimes contra a ordem tributária, econômica e contra as relações de consumo, e dá outras providências. Diário Oficial da União. Poder Legislativo. Brasília, DF, 28 dez. 1990, p. 1

BRASIL. Superior Tribunal de Justiça. Recurso em Habeas Corpus 8.320/SP, Relator Ministro Vicente Leal, Sexta Turma, julgado em 02/09/1999, publicado no Diário Oficial de 11/10/1999, p. 87. Disponível em: <www.stj.jus.br> Acesso em: 29 jul. 2015

FORGIONI, Paula Andréa. Direito Concorrencial e Restrições Verticais. São Paulo: RT, 2007

FORGIONI, Paula Andréa. Os Fundamentos do Antitruste. 3. ed. São Paulo: RT, 2008

GABAN, Eduardo Molan; Domingues, Juliana Oliveira. Direito Antitruste: o combate aos cartéis. 2. ed. São Paulo: Saraiva, 2009

LUCON, Paulo Henrique dos Santos. Repercussão geral (ausência). Prequestionamento (ausência). Ofensa indireta à Constituição Federal. Má-fé e ignorância. Danos decorrentes da demora do processo. In: WAMBIER, Tereza Arruda Alvim (coord.). Revista de Processo. n. 157. São Paulo: RT, 2008

NEVES, Marcelo. Ente Têmis e Leviatã: uma relação difícil. São Paulo: Martins Fontes, 2008 
NORTH, Douglas C. Economic Performance Through Time. The American Economic Review, vol. 84, n. 3, jun. 1994

OLIVEIRA, Gesner; RODAS, João Grandino. Direito e Economia da Concorrência. Rio de Janeiro: Renovar, 2004

PINHEIRO, Armando Castelar; SADDI, Jairo. Direito, Economia e Mercados. Rio de Janeiro: Elsevier, 2006

PINTO JÚNIOR, Mário Engler. O Antitruste e as Empresas Estatais. Revista de Direito Mercantil, n. 138, 2005

RIBEIRO, Márcia Carla Pereira. GALESKI JÚNIOR, Irineu. Teoria Geral dos Contratos: contratos empresariais e análise econômica. 2. ed. São Paulo: RT, 2015

RORTY, Richard. Contingência, Ironia e Solidariedade. Trad. Vera Ribeiro. São Paulo: Martins

ROSS, Alf. Direito e Justiça. Trad. Edson Bini. Bauru: Edipro, 2003

SALOMÃO FILHO, Calixto. Direito Concorrencial: as condutas. São Paulo: Malheiros, 2003

SALOMAO NETO, Eduardo. O Trust e o Direito Brasileiro. São Paulo: LTr, 1996

SZMID, Rafael. Interfaces entre o Direito Concorrencial e Propriedade Intelectual. Revista do IBRAC: Direito, Concorrência, Consumo e Comércio Internacional. Ano 18, vol 19, jan-jun, 2011 